\title{
Genetic mapping of the female mimic morph locus in the ruff
}

Lindsay L Farrell ${ }^{1,2^{*}}$, Terry Burke ${ }^{1}$, Jon Slate ${ }^{1}$, Susan B McRae ${ }^{3}$ and David B Lank ${ }^{2}$

\begin{abstract}
Background: Ruffs (Aves: Philomachus pugnax) possess a genetic polymorphism for male mating behaviour resulting in three permanent alternative male reproductive morphs: (i) territorial 'Independents', (ii) non-territorial 'Satellites', and (iii) female-mimicking 'Faeders'. Development into independent or satellite morphs has previously been shown to be due to a single-locus, two-allele autosomal Mendelian mode of inheritance at the Satellite locus. Here, we use linkage analysis to map the chromosomal location of the Faeder locus, which controls development into the Faeder morph, and draw further conclusions about candidate genes, assuming shared synteny with other birds.

Results: Segregation data on the Faeder locus were obtained from captive-bred pedigrees comprising 64 multigeneration families ( $N=381$ ). There was no evidence that the Faeder locus was linked to the Satellite locus, but it was linked with microsatellite marker Ppu020. Comparative mapping of ruff microsatellite markers against the chicken (Gallus gallus) and zebra finch (Taeniopygia guttata) genomes places the Ppu020 and Faeder loci on a region of chromosome 11 that includes the Melanocortin-1 receptor (MC1R) gene, which regulates colour polymorphisms in numerous birds and other vertebrates. Melanin-based colouration varies with life-history strategies in ruffs and other species, thus the MC1R gene is a strong candidate to play a role in alternative male morph determination.

Conclusion: Two unlinked loci appear to control behavioural development in ruffs. The Faeder locus is linked to Ppu020, which, assuming synteny, is located on avian chromosome 11. MC1R is a candidate gene involved in alternative male morph determination in ruffs.
\end{abstract}

\section{Background}

Evolving and maintaining genetic polymorphisms responsible for large phenotypic differences remains a subject of interest, despite $>70$ years of study (e.g. $[1,2]$ ). Genomic methods now enable polymorphisms to be described down to the genetic and molecular expression levels (e.g. [3]). Ruffs (Philomachus pugnax) possess three distinct permanent alternative male reproductive morphs that differ in territorial lekking behaviour, plumage colour, and size: dark-plumed territorial 'Independents', white-plumed non-territorial 'Satellites' and small female mimic 'Faeders' that lack display plumage and behaviour [4-7]. Development into independent or satellite morphs has been previously shown to be due to a genetic polymorphism consistent with a single-locus, two-

\footnotetext{
* Correspondence: Ifarrell@sfu.ca

${ }^{1}$ Department of Animal and Plant Sciences, University of Sheffield, Sheffield, S10 2TN, UK

${ }^{2}$ Department of Biological Sciences, Simon Fraser University, Burnaby, BC V5A 156, Canada

Full list of author information is available at the end of the article
}

allele autosomal Mendelian mode of inheritance at the Satellite locus, with a dominant $S$ allele producing satellites $[8,9]$. Genetically, independent males are homozygous recessive at the Satellite locus and ca $90 \%$ of satellites should be heterozygotes [8]. Remarkably, only as recently as 2006 , a third morph was discovered: faeder males resemble large females, completely lacking any ornamental breeding plumage during the breeding season [5] (Figure 1). It was recently reported that a dominant allele controls development into both faeders and diminutive females, coined 'faeder females' [10]. Whether the faeder allele is at the same Satellite locus, or a separate locus, has yet to be determined, as more detailed pedigree-based genetics of the newly discovered morph are not yet available.

Prior to each breeding season, independent and satellite males grow ornamental plumage that includes a feather 'ruff' and 'head tufts', which are each individually distinctive in colour and pattern and fixed for life [11,12]. At leks, independents establish and defend small breeding courts where they perform a variety of territorial threat displays

\section{() Biomed Central}




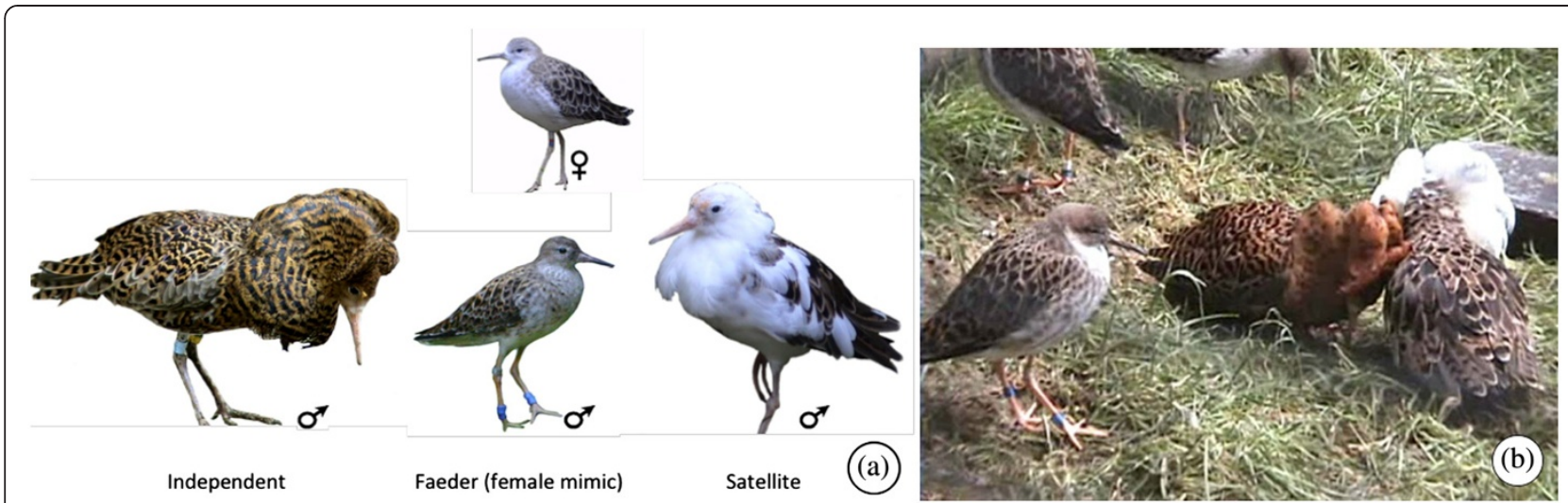

Figure 1 (a) Three permanent alternative male reproductive morphs of ruff (Philomachus pugnax) associated with territorial lekking behaviour and plumage colour. Pictured bottom left: territorial dark-plumed 'Independent'; bottom middle: female mimic 'Faeder'; bottom right: non-territorial white-plumed 'Satellite'; top middle: female (photos by L.L.F and S.B.M). (b) On a captive lek, the independent and satellite males are displaying (right) with the faeder male near by (left) (photo by S.B.M).

and fight against other independents. The white-plumed satellites do not hold territories, are rarely aggressive, and are actively courted into co-displaying on courts held by independents, apparently due to female preference for male-male cooperation on leks $[4,6,7,13,14]$ and a high rate of polyandry [15]. In contrast to both classes of ornamented males, faeder males grow breeding plumage that is similar to that of females-lacking display feathers-and aggregate close to displaying males to 'sneak' copulations with females and interfere with copulation attempts by other males ([5]; Lank et al. unpublished) (Figure 1). Females believed to be carrying the dominant Faeder allele form a distinct small size mode [10]. Normal-sized females carrying the dominant Satellite allele can be identified from the phenotype ratios of their male offspring when mated to independent males, and/or confirmed with observations of behaviour and ornamental plumage growth when implanted with testosterone [9].

Recently, a microsatellite linkage map for the ruff was constructed, identifying seven linkage groups and a further five single-marker loci homologous to locations on known chicken (Gallus gallus) and zebra finch (Taeniopygia guttata) chromosomes [16]. As a step towards identifying the genes underlying the morph polymorphisms, we attempted to map the causal satellite and faeder loci by using linkage analysis to identify markers that co-segregated with each morph type in a pedigreed and phenotyped breeding population.

\section{Methods}

Pedigree, phenotype, and microsatellite information were available from 381 individuals from a captive population of ruffs spanning fourteen breeding years and comprising 64 families $(N=381$ individuals, $[10,16])$. In total, 167 individuals were included for the Satellite locus: 129 assigned as independents (120 males, 9 females), 38 satellites (35 males, 3 females) and 381 individuals for the Faeder locus: 43 faeders (24 males, 19 females) and 338 non-faeders (155 males, 183 females).

This research was conducted at Simon Fraser University under approval of the Animal Care Committee.

\section{Linkage analysis}

Separate autosomal genetic models for the two male behavioural polymorphisms (Satellite versus Independent; Faeder versus Not Faeder) were tested in CRIMAP v.2.4 [17] using phenotypic and pedigree data to assign putative genotypes separately for both the Satellite and Faeder loci. For the Satellite locus: independent males $(N=120)$ were coded as homozygous recessive $(s s)$ and satellite males $(N=35)$ coded with the dominant $S$ allele $\left(S_{-}\right)$, with faeders not coded at this locus. A small number of females $(N=12)$ were assigned a satellite or independent behavioural morph and putative genotype based on pedigree analysis of their male offspring morph ratios when mated with an independent male (Lank et al. unpublished). Females mated with an independent male that produced mixed offspring were designated as heterozygotes $(S s, N=3)$, and females with a high number of offspring $(N=11-22)$ who failed to produce any satellites when mated with independents were designated as homozygous recessive at the Satellite locus (ss, $\mathrm{N}=9$ ). In the majority of cases, these morph assignments were confirmed with testosterone-induced behavioural data [9]. For the Faeder locus: both independent and satellite males were coded as homozygous recessive (ff, $N=155$ ) and faeder males as $\left(F_{-}\right)$, indicating that they carry at least one copy of the $F$ allele $(N=24)$ [10]. Since the faeder frequency in natural populations is $\mathrm{ca}$ $1 \%[5,18-20]$, the probability of observing homozygous faeders in the wild is low. Faeders in the captive 
population were derived from 2 wild-caught founders. Both of these males produced both faeder and nonfaeder offspring when mated exclusively with females from non-faeder lineages, as did their sons. No faeder daughters are included as mothers in these analyses. For females, phenotypic assignments as 'faeder females' $(N=19)$ were made through principal component analysis of size distributions based on tarsus, culmen, and minimum mass [10]. All non-faeder females $(N=183)$ were coded as homozygous recessive $(f f)$, and faeder females coded as $\left(F_{-}\right)$for similar reasons as were the males.

A test for linkage between the Satellite locus and Faeder locus, and all microsatellite markers $(N=58)$ used in the ruff microsatellite linkage map [16], was performed by means of the two-point function in CRIMAP, with a LOD score $>3.0$ being taken as evidence of linkage. The Satellite and Faeder loci were first run separately, then together in CRIMAP. We used comparative mapping [21,22] of microsatellite markers used in the ruff microsatellite linkage map [16] against the chicken and zebra finch genome assemblies to search for possible candidate genes in the genomic location close to any microsatellites that were linked to the ruff Faeder locus.

\section{Results and discussion}

No linkage was detected between the Satellite and Faeder loci, and the Satellite locus was unlinked to any other marker in twopoint analysis. The latter result may be due in part to the low number of satellites with heterozygous genotypes and high number of independents contained within the pedigree, resulting in a small number of informative meioses at the target Satellite locus. Out of the total 167 individuals with inferred genotypes at the Satellite locus, 129 of these were independents and 38 were satellites. The non-linkage of the two behavioural loci, Satellite and Faeder, to the same marker or, more importantly, to each other, indicates that two independent loci determine alternative morph development in ruffs. Additional genotyping of satellite individuals and/or more detailed pedigree data will further test this two-locus model.

Several species with three heritable alternative mating phenotypes have been described (e.g., [23]), but explicit mendelian models have been best tested for the marine isopod Paracerceis sculpta [24], for which a 1-locus 3allele model with hierarchical dominance was supported. Remarkably, alleles coding for 'alternative' morphs in these other systems are dominant to those of the presumed ancestral allele, as they are in the ruff [10]. In the ruff, this suggests a sequence for invasion by these derived morphs, with faeders following satellites.

In the twopoint analyses, the Faeder locus was strongly linked to microsatellite marker Ppu020 with a LOD score 8.24 and recombination fraction of 0.03 . This locus was not placed on the ruff linkage map but comparative mapping has shown it to be on chromosome 11 [16]. Further linkage analysis with microsatellite markers on chromosome 11 was not possible, however, due to the small number of markers genotyped on this chromosome in the ruff linkage map [16].

By comparative mapping [21,22] of ruff microsatellite markers [25] to the chicken and zebra finch genome assemblies (Figure 2), an obvious candidate locus was identified. The Melanocortin-1 receptor (MC1R) gene, an important pigment-regulating gene in birds and numerous other vertebrates, is located on chromosome 11 in both species. In chicken, the distance between Ppu02O and $M C 1 R$ is $1.2 \mathrm{Mb}$ and, in zebra finch, the distance is $20.7 \mathrm{Mb}$ (Figure 2).

Although ruff microsatellite Ppu020 is not included in the ruff linkage map for chromosome 11, two further ruff microsatellite loci have been assigned to this chromosome by in silico comparative mapping [25]. Comparison of the locations of these markers in the zebra finch and chicken genomes indicates that there was an intrachromosomal rearrangement of this region of chromosome 11 in an unknown lineage since the divergence of the ancestors of chicken and zebra finch (Figure 2). Therefore, inferring the physical distance between $M C 1 R$ and the Faeder locus in ruffs is not straightforward, especially as no species in the ruff's avian superorder (the Charadriiformes) has yet been the subject of a full genome sequencing project.

\section{Conclusion}

Regardless of the precise location of $M C 1 R$ in ruffs, we conclude that this gene and those in proximity to it are candidates for the Faeder locus. Melanin-based colouration has previously been shown to be associated with morphology, physiology, life-history strategies and behaviour in several bird species (e.g., [26-28]), including ruffs, as well as having correlated fitness-related effects in other vertebrates $[29,30]$.

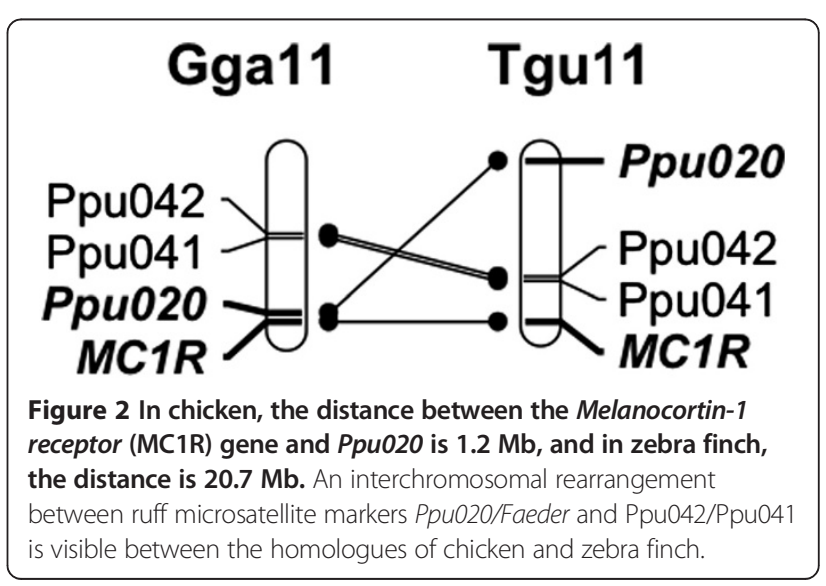




\section{Competing interests}

The authors declare no competing interests.

\section{Authors' contributions}

LLF designed the study, performed the laboratory work, completed the data analysis, and drafted and revised the manuscript. DBL, TB and JS helped with the design of the study, the interpretation of the data, and with drafting and revision of the manuscript. JS and TB conceived coding the faeder behaviour locus into the linkage map. SBM contributed to the development of the ruff pedigree and quantifying faeder phenotypes with DBL. All authors read and approved the final manuscript.

\section{Acknowledgements}

During this work, LLF was a PhD student in the department of Biological Sciences at Simon Fraser University. The laboratory work was performed at the University of Sheffield and supported by a UK Biotechnology and Biological Sciences Research Council grant to TB and JS. The captive ruff colony was supported by a Natural Sciences and Engineering Research Council of Canada grant (NSERC; to DBL), and LLF was supported by an NSERC PGS-D3.

\section{Author details}

${ }^{1}$ Department of Animal and Plant Sciences, University of Sheffield, Sheffield, S10 2TN, UK. ²Department of Biological Sciences, Simon Fraser University, Burnaby, BC V5A 1S6, Canada. ${ }^{3}$ Department of Biology and Center for Biodiversity, East Carolina University, Greenville, NC 27858-4353, USA.

Received: 29 July 2013 Accepted: 11 November 2013

Published: 20 November 2013

\section{References}

1. Chevin LM, Lande R: Evolution of discrete phenotypes from continuous norms of reaction. Am Nat 2013, 182:13-27. doi:10.1086/670613.

2. Dobzhansky T: Genetics of the Evolutionary Process. New York: Columbia University Press; 1970.

3. Cheviron ZA, Whitehead A, Brumfield RT: Transcriptomic variation and plasticity in rufous-collared sparrows (Zonotrichia capensis) along an altitudinal gradient. Mol Ecol 2008, 17:4556-4569.

4. Hogan-Warburg AJ: Social behavior of the ruff (Philomachus pugnax). Ardea 1966, 54:108-229.

5. Jukema J, Piersma T: Permanent female mimics in a lekking shorebird. Biol Lett 2006, 2:161-164

6. Van Rhijn JG: Behavioural dimorphism in male ruffs Philomachus pugnax (L.). Behaviour 1973, 47:153-229.

7. Van Rhijn JG: The Ruff. London: Poyser; 1991.

8. Lank DB, Smith CM, Hanotte O, Burke T, Cooke F: Genetic polymorphism for alternative mating behaviour in lekking male ruff, Philomachus pugnax. Nature 1995, 378:59-62.

9. Lank DB, Coupe M, Wynne-Edwards KE: Testosterone-induced male traits in female ruffs (Philomachus pugnax): autosomal inheritance and gender differentiation. Proc R Soc Lond B 1999, 266:2323-2330.

10. Lank DB, Farrell LL, Burke T, Piersma T, McRae SB: A dominant allele controls development into female mimic male and diminutive female ruffs. Biol Lett 2013. doi:10.1098/rsbl.2013.0653.

11. Dale J, Lank DB, Reeve HK: Signalling individual identity versus quality: a model and case studies with ruffs, queleas, and house finches. Am Nat 2001, 158:75-86.

12. Lank DB, Dale J: Visual signals for individual identification: the silent "Song" of ruffs. Auk 2001, 118:759-765.

13. Hugie DM, Lank DB: The resident's dilemma: a female choice model for the evolution of alternative mating strategies in lekking male ruffs (Philomachus pugnax). Behav Ecol 1997, 2:218-223.

14. Widemo F: Alternative reproductive strategies in the ruff Philomachus pugnax: a mixed ESS? Anim Behav 1998, 56:329-333.

15. Lank DB, Smith CM, Hanotte O, Ohtonen A, Bailey S, Burke T: High frequency of polyandry in a lek mating system. Behav Ecol 2002, 2:209-215.

16. Farrell LL, Burke T, Slate J, Lank DB: A first-generation microsatellite linkage map of the ruff. Ecol Evol 2013. doi:10.1002/ece3.830.

17. Green P, Falls K, Crooks S: CRIMAP Documentation, version 2.4. St. Louis: Washington University School of Medicine; 1990
18. Jaatinen $K$, Lehikoinen $A$, Lank DB: Female-biased sex ratios and the proportion of cryptic male morphs of migrant juvenile ruffs (Philomachus pugnax) in Finland. Orn Fenn 2010, 87:125-134.

19. Karlionova N, Pinchuk $P$, Meissner W, Verkuil Y: Biometrics of ruffs Philomachus pugnax migration in spring through southern Belarus with special emphasis on the occurance of 'faeders'. Ring Migr 2007, 23:134-140

20. Verkuil YI, Jukema J, Gill JA, Karlionova N, Melter J, Hooijmeijer JCEW, Peirsma T: Non-breeding faeder ruffs Philomachus pugnax associate according to sex, not morphology. Bird Study 2008, 55:241-246.

21. Dawson DA, Burke T, Hansson B, Pandhal J, Hale MC, Hinten GH, Slate J: A predicted microsatellite map of the passerine genome based on chicken-passerine sequence similarity. Mol Ecol 2006, 5:1299-1320.

22. Dawson DA, Åkesson M, Burke T, Pemberton JM, Slate J, Hansson B: Gene order and recombination rate in homologous chromosome regions of the chicken and a passerine bird. Mol Biol Evol 2007, 7:1537-1552.

23. Sinervo B, Bleay C, Adamopoulou C: Social causes of correlational selection and the resolution of a heritable throat color polymorphism in a lizard. Evolution 2001, 55:2040-2052.

24. Shuster SM, Sassaman C: Genetic interaction between male mating strategy and sex ratio in a marine isopod. Nature 1997, 388:373-377.

25. Farrell LL, Dawson DA, Horsburgh GJ, Burke T, Lank DB: Isolation, characterization and predicted genome locations of ruff (Philomachus pugnax, AVES) microsatellite loci. Cons Gen Res 2012, 4:763-771. doi:10.1007/s12686-012-9639-0.

26. Ducrest AL, Keller L, Roulin A: Pleiotropy in the melanocortin system, coloration and behavioral syndromes. Trends Ecol Evol 2008, 23:502-510.

27. Roulin A, Bize P, Ravussin P, Broch L: Genetic and environmental effects on the covariation between colour polymorphism and a life-history trait. Evol Ecol Res 2004, 6:1253-1260.

28. Silva AD, van den Brink V, Emaresi G, Luzio E, Bize P, Dreiss AN, Roulin A: Melanin-based colour polymorphism signals aggressive personality in nest and territory defence in the tawny owl (Strix aluco). Behav Ecol Sociobiol 2013, 67:1041-1052

29. Anderson NG, Nagaeva O, Mandrika I, Petrovska R, Muceniece R, MinchevaNilsson LM, Wikberg JES: $M_{1}$ receptors are constitutively expressed on leucocyte subpopulations with antigen presenting and cytotoxic functions. Clin Exp Immunol 2001, 3:441-446.

30. Hoekstra HE: Genetics, development and evolution of adaptive pigmentation in vertebrates. Heredity 2006, 97:222-234.

doi:10.1186/1471-2156-14-109

Cite this article as: Farrell et al:: Genetic mapping of the female mimic morph locus in the ruff. BMC Genetics 2013 14:109.

\section{Submit your next manuscript to BioMed Central and take full advantage of:}

- Convenient online submission

- Thorough peer review

- No space constraints or color figure charges

- Immediate publication on acceptance

- Inclusion in PubMed, CAS, Scopus and Google Scholar

- Research which is freely available for redistribution 